\title{
Plasminogen Activator Inhibitor-1 in Girls with Precocious Pubarche: A Premenarcheal Marker for Polycystic Ovary Syndrome?
}

\author{
LOURDES IBÁÑEZ, CARLES AULESA, NEUS POTAU, KEN ONG, DAVID B. DUNGER, AND \\ FRANCIS DE ZEGHER \\ Endocrinology Unit, Hospital Sant Joan de Déu, University of Barcelona, Barcelona, Spain [L.I.]; \\ Department of Biochemistry [C.A.] and Hormonal Laboratory [N.P.], Hospital Materno-Infantil Vall \\ d'Hebron, Autonomous University of Barcelona, Barcelona, Spain; Department of Paediatrics, University \\ of Cambridge, Cambridge, United Kingdom [K.O., D.B.D.]; Department of Pediatrics, University of \\ Leuven, Leuven, Belgium [F.d.Z.]
}

\begin{abstract}
In both obese and nonobese women, polycystic ovary syndrome (PCOS) is essentially a disorder of hyperinsulinemic insulin resistance, and it may be heralded by precocious pubarche (PP; appearance of pubic hair in girls aged $<8 \mathrm{y}$ ). The risk of progression from PP to PCOS is related to low birth weight, but there are no early biochemical markers of this risk. As increased plasminogen activator-inhibitor type 1 (PAI-1) activity (act) is an early marker of cardiovascular risk in PCOS, we have sought abnormalities in young girls with PP. In 33 young PP girls (age range 6-11 y), PAI-1-act was increased (mean + SEM: $15.6 \pm$ $1.5 \mathrm{IU} / \mathrm{mL}$ ) compared with age-, sex-, and pubertal stagematched controls $(n=13,10.7 \pm 1.9, p<0.05)$. PAI- 1 -act levels were inversely related to birth weight SD score $(r=$ $-0.33, p<0.05)$, and PAI-1-act levels were therefore higher in PP girls with low birth weights $(n=14,19.5 \pm 2.5 \mathrm{IU} / \mathrm{mL})$ than normal birth weights $(n=19,12.8 \pm 1.5, p<0.01)$. During longitudinal observation in $10 \mathrm{PP}$ girls (mean time interval
\end{abstract}

\section{ABSTRACT}

2.7 y), PAI-1-act levels in early puberty were positively related to postmenarcheal insulin levels (mean serum insulin SDS postoral glucose, $r=0.65, p<0.05)$, and showed a similar relationship to postmenarcheal testosterone levels $(r=0.61, p=$ 0.06). Together with low birth weight, increased plasma PAI-1act levels in early pubertal PP girls may indicate those girls with greater risk of developing hyperinsulinemic-hyperandrogenism features of PCOS. (Pediatr Res 51: 244-248, 2002)

Abbreviations
PCOS, polycystic ovary syndrome
PP, precocious pubarche
PAI-1, plasminogen activator-inhibitor type 1
PAI-1-act, plasminogen activator-inhibitor type 1 activity
t-PA, tissue plasminogen activator
DHEAS, dehydroepiandrosterone-sulfate

Girls with PP [appearance of pubic hair before 8 y (1)] due to pronounced adrenarche are known to be at risk for hyperinsulinism, dyslipidemia, and, in postmenarche, ovarian hyperandrogenism (2-5). These endocrine-metabolic abnormalities are reminiscent of those seen in PCOS, and may be associated with increased risk of adulthood type 2 diabetes and cardiovascular disease (6-10). The link with these PCOS-like features is particularly marked when PP has been preceded by prenatal growth restraint $(11,12)$. Recent evidence indicates

Received March 28, 2001; accepted October 19, 2001.

Correspondence and reprint requests: Lourdes Ibáñez, M.D., Endocrinology Unit, Hospital Sant Joan de Déu, University of Barcelona, Passeig de Sant Joan de Déu, 2, 08950 Esplugues, Barcelona, Spain; e-mail: libanez@hsjdbcn.org

Supported by a Visiting Scholarship from the European Society for Paediatric Endocrinology and by the Agència per a la Recerca i la Docència from the Hospital Materno-Infantil Vall d'Hebron, Barcelona, Spain.

F.d.Z. is a Clinical Research Investigator of the Fund for Scientific Research, Flanders, Belgium. that an insulin-sensitizing treatment can reverse these endocrine-metabolic abnormalities in adolescent girls who experienced the sequence from reduced prenatal growth, through PP, to a PCOS-like condition, and this finding supports the concept that insulin resistance plays a key role in the pathogenesis of this sequence (13). However, in longitudinal studies of PP girls, the full endocrine-metabolic abnormalities conferred by reduced prenatal growth may not be manifested until late puberty or postmenarche (14), and there are no biochemical markers in early puberty that indicate the long-term risk for progression to PCOS and associated cardiovascular disease.

PAI-1 is a major inhibitor of fibrinolysis (15); it binds and inactivates both t-PA and urokinase-type plasminogen activator (15). PAI-1 and fibrinogen are well-recognized risk markers for cardiovascular disease including myocardial infarction (16-19), and high circulating levels of these parameters are associated with insulin resistance in several populations includ- 
ing low-birth weight men, women with PCOS, nondiabetic subjects, and patients with type 2 diabetes $(20-28)$. We have therefore examined whether circulating PAI-1 and/or fibrinogen levels are raised in PP girls, and, in particular, whether PAI-1 levels in early puberty are related to low birth weight and may thus indicate higher risk of PCOS-like abnormalities postmenarche.

\section{STUDY DESIGN, SUBJECTS, AND METHODS}

Study design. This study consists of cross-sectional and longitudinal parts.

In the cross-sectional study, we assessed whether circulating levels of fibrinogen, PAI-1, and t-PA were different in PP and non-PP girls, and, furthermore, whether these levels were different in premenarcheal PP girls with low birth weight (high risk for subsequent hyperinsulinism-hyperandrogenism) from those with normal birth weight (low risk).

In a smaller longitudinal study, we prospectively verified whether any cross-sectionally identified premenarcheal marker correlated with postmenarcheal markers of hyperinsulinism-hyperandrogenism.

Subjects. In the cross-sectional study, a total of 46 girls (age range 6-11 y) were enrolled, of whom 33 presented with PP, and 13 girls without PP (these were mostly evaluated for short-normal stature and were subsequently considered to be healthy). The two subgroups were matched for age and pubertal stage, all girls being either prepubertal or in early puberty [Tanner breast stage II-III (29)].

Body mass indexes were normal in all subjects (30) and were transformed into SD scores, according to population references $(3,11)$. Birth weight and gestational age data in PP girls were obtained from hospital records and transformed into gestational-age adjusted SD scores, as previously described (11).

The PP cohort was divided into normal- and low-birth weight subgroups according to a cut-off level of $-1.5 \mathrm{SD}(\sim 2.7$ $\mathrm{kg}$ at term birth), a level of prenatal growth restraint that has previously been associated with hyperinsulinism and ovarian hyperandrogenism in adolescent girls with a history of PP (11).

Glucose and insulin levels of part of this study population have previously been reported in cross-sectional studies (3, 11). Girls with PP were only included in the study when PP was secondary to exaggerated adrenarche, as suggested by elevated serum androstenedione and/or DHEAS levels $(1,31)$, and corroborated by an ACTH test to exclude nonclassic adrenal hyperplasia $(32,33)$; none of the girls had acanthosis nigricans, thyroid dysfunction, Cushing syndrome, or a family or personal history of diabetes mellitus, and none was receiving a medication known to affect carbohydrate or lipid metabolism.

The longitudinal study cohort comprised of 10 of the early pubertal PP girls of the cross-sectional study, who were followed and reassessed postmenarche (mean time interval $2.7 \mathrm{y}$ ).

All subjects had normal glucose tolerance, according to criteria of the Expert Committee on the Diagnosis and Classification of Diabetes Mellitus (34). This study was approved by the Institutional Review Board of Barcelona Hospital, and informed consent was obtained from parents, as well as assent from the girls.

Endocrine-metabolic assessment. Standard $1.75 \mathrm{~g} / \mathrm{kg}$ (maximum $75 \mathrm{~g}$ ) 2-h oral glucose tolerance tests (oGTT, starting at $0800 \mathrm{am}$ ) were performed after $3 \mathrm{~d}$ on a high-carbohydrate diet $(300 \mathrm{~g} / \mathrm{d})$ and an overnight fast. Blood was sampled $0,30,60$, and $120 \mathrm{~min}$ after oral glucose intake, for measurement of glucose and immunoreactive insulin, as previously described (2). For calculation of mean serum insulin (MSI) during the oGTT, the area under the insulin curve was calculated according to the trapezoidal rule. Individual MSI levels were transformed into SD scores (2).

Serum testosterone and sex hormone-binding globulin (SHBG) were measured in baseline oGTT blood samples. To minimize the effect of diurnal variation on PAI-1 levels (35), fasting blood samples were drawn between $0730-0800 \mathrm{~h}$ for fibrinogen measurement, for determination of the plasma antigen concentrations of PAI-1 and t-PA, and for assessment of the functional activity of PAI-1 (PAI-1act). The samples were collected in standard Vacutainer tubes containing $0.105 \mathrm{M}$ sodium citrate to prevent release of platelet PAI-1, were immediately placed on ice, and centrifuged within $30 \mathrm{~min}$.

Hormonal assays. Plasma antigen concentrations of PAI-1 and t-PA were determined by ELISA (Tintelize, Biopool, Umeä, Sweden), with the use of antibodies that detected PAI-1 and t-PA in both the free and the complexed state; the mean intra-and interassay coefficients of variation (CVs) were 3.5\% and $6.8 \%$ for PAI- 1 , and $4.5 \%$ and $9.1 \%$ for t-PA. PAI- 1 -act was determined with a chromogenic substrate of plasmine (HRP, Chromolize, Biopool) reporting to which extent an aliquot of plasma inhibited t-PA-induced activation of plasminogen (36). Plasma fibrinogen concentration was determined by nephelometric assay (28) and serum glucose was measured by the glucose oxidase method. Immunoreactive insulin was assayed by IMX (Abbott Diagnostics, Santa Clara, CA, U.S.A.). The mean intra- and interassay CVs were $4.7 \%$ and $7.2 \%$. Serum testosterone was determined using a commercially available RIA kit, and SHBG was measured by enzymo-immuno-chemiluminescence (13). Serum samples were kept frozen at $-70^{\circ} \mathrm{C}$ until assay.

Statistics. Results are expressed as mean \pm SEM. Between group differences (PP versus controls; low birth weight versus normal birth weight), were examined using $t$ tests for normally distributed data, and Mann-Whitney U tests for hormone levels that showed nonparametric distributions. Positively skewed hormonal data were transformed to normal distributions by calculating natural logarithms to allow the use of parametric tests of correlation.

\section{RESULTS}

Results of the cross-sectional study are summarized in Table 1. As expected (2), fasting glucose-insulin ratios, glucoseinduced insulin responses, SHBG, and testosterone differed between control and PP girls. Plasma PAI-1 antigen concentrations and PAI-1-act were both elevated in PP girls compared with controls, whereas there were no differences in fibrinogen and t-PA levels (Table 1, left columns). 
Table 1. Clinical, endocrine-metabolic, and hemostatic variables in prepubertal and early pubertal control girls and girls with PP. The PP girls were also subgrouped according to birth weight SD score.

\begin{tabular}{|c|c|c|c|c|}
\hline & \multicolumn{2}{|c|}{ Total } & \multicolumn{2}{|c|}{ PP } \\
\hline & Control $(n=13)$ & $\mathrm{PP}(n=33)$ & $\begin{array}{c}\text { Normal birth weight } \\
\quad(n=19)\end{array}$ & $\begin{array}{l}\text { Low birth weight } \\
\quad(n=14)\end{array}$ \\
\hline Age (y) & $9.2 \pm 0.6$ & $9.1 \pm 0.3$ & $9.0 \pm 0.4$ & $9.3 \pm 0.4$ \\
\hline Glucose/insulin ratio & $13.3 \pm 1.5$ & $9.6 \pm 0.7 \dagger$ & $10.2 \pm 0.8$ & $9.4 \pm 1.1$ \\
\hline BMI $\left(\mathrm{kg} / \mathrm{m}^{2}\right)$ & $17.9 \pm 0.5$ & $18.2 \pm 0.4$ & $18.2 \pm 0.4$ & $18.4 \pm 0.7$ \\
\hline MSI (mU/L) & $33.8 \pm 3.1$ & $56.0 \pm 4.7 \dagger$ & $53.5 \pm 6.4$ & $59.4 \pm 7.0$ \\
\hline Testosterone (nmol/L) & $0.3 \pm 0.04$ & $0.7 \pm 0.1 \S$ & $0.7 \pm 0.2$ & $0.8 \pm 0.1$ \\
\hline Fibrinogen $(\mathrm{g} / \mathrm{L})$ & $2.9 \pm 0.1$ & $3.4 \pm 0.2$ & $3.4 \pm 0.2$ & $3.3 \pm 0.2$ \\
\hline PAI-1 ag (ng/mL) & $21.9 \pm 3.2$ & $38.5 \pm 3.4 \dagger$ & $34.6 \pm 3.6$ & $44.3 \pm 6.2$ \\
\hline PAI-1-act (IU/mL) & $10.7 \pm 1.9$ & $15.6 \pm 1.5 \S$ & $12.8 \pm 1.5$ & $19.5 \pm 2.5^{*}$ \\
\hline t-PAag $(\mathrm{ng} / \mathrm{mL})$ & $4.2 \pm 0.5$ & $4.8 \pm 0.4$ & $4.6 \pm 0.6$ & $5.1 \pm 0.7$ \\
\hline
\end{tabular}

Values are mean \pm SEM.

BMI, body mass index; MSI, mean serum insulin after oral glucose tolerance test; SHBG, sex hormone-binding globulin; PAI-1, plasminogen-activator inhibitor type 1 antigen (ag) and activity (act); t-PAag, tissue-plasminogen activator antigen.

$\S p<0.05, \dagger p \leq 0.01$, and $\$ p \leq 0.001 v s$. controls.

$* p \leq 0.01$, and $q p \leq 0.001$ vs. the normal birthweight PP subgroup.

However, most of these endocrine-metabolic variables were no different between PP subgroups with low versus normal birth weights; this was also true for fibrinogen, PAI-1 antigen, and t-PA antigen levels. PAI-1-act was the only assessed biochemical variable that distinguished low- from normal-birth weight PP girls at this early age (Table 1, right columns). In all girls, we observed a significant inverse correlation between PAI-1-act levels and birth weight SD score $(r=-0.33, p=$ 0.03 ), and in a multiple regression analysis this relationship between PAI-1-act levels and birth weight SD score was independent of MSI SDS ( $\beta=-0.38, p=0.02)$.

In the longitudinal study of $10 \mathrm{PP}$ girls, postmenarcheal assessment focused on glucose-induced hyperinsulinism, which is thought to drive the association with hyperandrogenism (13). Table 2 displays individual birth weight SD scores, premenarcheal PAI-1-act levels and postmenarcheal MSI and testosterone levels. In these 10 girls, the close corre-

Table 2. Longitudinal measures in girls with $P P(n=10$; mean interval $2.7 y$ )

\begin{tabular}{cccc}
\hline $\begin{array}{c}\text { Early pubertal } \\
\text { PAI-1-act (IU/mL) }\end{array}$ & $\begin{array}{c}\text { Postmenarcheal } \\
\text { Birthweight SD }\end{array}$ & $\begin{array}{c}\text { Postmenarcheal } \\
\text { MSI (mU/L) }\end{array}$ & $\begin{array}{c}\text { testosterone }(\mathrm{nmol} / \mathrm{L}) \\
\text { 12.9 }\end{array}$ \\
\hline 14.5 & -0.26 & 45.6 & 1.9 \\
15.8 & 0.00 & 60.0 & 1.6 \\
15.9 & -1.83 & 68.8 & 1.1 \\
19.9 & 0.00 & 26.5 & 1.1 \\
21.0 & -0.29 & 72.4 & 1.3 \\
21.3 & 0.13 & 123.7 & 1.5 \\
21.9 & -4.22 & 118.4 & 2.9 \\
26.3 & -3.01 & 86.5 & 2.1 \\
29.7 & -2.21 & 97.1 & 2.6 \\
\hline $19.9 \pm 1.7$ & $-1.2 \pm 0.5$ & $77.5 \pm 9.1$ & 2.4 \\
\hline
\end{tabular}

Early pubertal age: $10.3 \pm 0.2 \mathrm{y}$; postmenarcheal age: $13.0 \pm 0.2 \mathrm{y}$.

MSI, (mean serum insulin) after an oral glucose tolerance test.

Body mass index (BMI) SD were similar in early puberty and postmenarche $(0.01 \pm 0.2$ vs. $0.36 \pm 0.2)$.

* Reference values for our age- and BMI-matched population (mean \pm SEM): $1.1 \pm 0.1(2)$. lation between postmenarcheal MSI SD scores and postmenarcheal serum concentrations of testosterone was confirmed $(r=0.87, p=0.001)$.

More importantly, PAI-1-act levels in early puberty were positively related to postmenarcheal MSI SD score $(r=0.65$, $p=0.04$ ), a measure of postmenarcheal hyperinsulinism; PAI-1-act levels in early puberty also showed a similar nearsignificant relationship to postmenarcheal testosterone levels $(r=0.61, p=0.06)$.

\section{DISCUSSION}

There is emerging consensus that, in both obese and nonobese women, PCOS is essentially a disorder of hyperinsulinemic insulin resistance, possibly with onset in early life. PP has been established as a major risk factor for PCOS from adolescence onwards, particularly if PP itself was preceded by a low birth weight. Accordingly, PP is currently explored as a model to study incipient PCOS $(4,14)$. However, previous studies have failed to identify, in young PP girls, an endocrine or metabolic variable that might serve as a prepubertal or early pubertal marker for subsequent PCOS and, ultimately, for type 2 diabetes and cardiovascular disease (14).

We now report cross-sectional and longitudinal data from PP girls that points to high premenarcheal plasma concentrations of PAI-1-act as a prime candidate marker for subsequent PCOS and its endocrine-metabolic correlates.

We found that PAI-1-act levels before or early after onset of puberty were higher in low-birth weight PP girls (high PCOS risk) than normal-birth weight PP girls (low PCOS risk); the former showed PAI-1-act levels in the range of obese adult PCOS women (37); and in a smaller longitudinal sample these PAI-1-act levels correlated significantly with postmenarcheal hyperinsulinism, which in turn is known to drive ovarian hyperandrogenism $(11,13,14,38)$. Although our longitudinal cohort was small, and the relationship between early pubertal PAI-1-act and postmenarcheal testosterone did not quite reach statistical significance $(p=0.06)$, these findings are entirely 
consistent with those of the cross-sectional study and our data confirm previous reports $(20-28,37,39,40)$ showing that PAI levels are raised in PCOS and in other insulin resistance-related conditions.

Epidemiologic studies have established the strong interrelationship between plasma PAI-1 and t-PA $(19,23,41,42)$. However, only a minor fraction of circulating t-PA is functionally active, the major fraction being complexed to PAI-1; in the presence of PAI-1, circulating t-PA is rapidly inactivated and cleared (42). Hence, the concept that a high plasma PAI-1-act, rather than a low plasma t-PA, may become an early marker heralding PCOS is in line with current pathophysiological principles and is supported by reports showing that a high plasma PAI-1-act level predicts cardiovascular disease more accurately than a low plasma t-PA level, particularly in individuals with other components of the insulin resistance syndrome $(19,42)$.

Plasma PAI-1-act levels are negatively associated with age (43) and co-determined by insulinemia and by polymorphisms in the promoter region of the PAI-1 gene $(19,43,44)$. Heterozygosity or homozygosity for the $4 \mathrm{G}$ polymorphism of the PAI-1 gene is consistently associated with increased PAI-1-act levels (40). This genotype is much more common in women with PCOS (40), and has been shown to be an independent risk factor for miscarriage and pregnancy complications, both in normal and PCOS women $(45,46)$. The contribution of the PAI-1 genotype to PAI-1 levels depends on the co-existence of hyperinsulinemia and dyslipidemia $(19,47)$. Insulin augments PAI-1 expression in vitro and PAI-1-act in vivo (48-50); attenuation of hyperinsulinemia by weight loss and/or by an insulin-sensitizing treatment decreases circulating PAI-1, including in PCOS women $(38-40,51)$.

The purported insulin-induced increases in PAI-1 synthesis and secretion are exerted through a synergy of insulin and triglycerides, in concert with LDLs $(19,48-50,52)$. In lowbirth weight PP girls, the circulating levels of triglycerides and LDL cholesterol are higher than in normal-birth weight PP girls in early puberty, although their characteristic hyperinsulinism is not readily discernible until postmenarche (14). Thus, the early discriminative capacity of PAI-1-act levels may result from a synergistic amplification of subtle premenarcheal differences in both hyperinsulinism and dyslipidemia.

Long-term hyperinsulinemia is known to increase circulating fibrinogen levels $(26,53)$. In this cohort of premenarcheal PP girls, plasma fibrinogen concentrations were not significantly elevated compared with control girls. However, 10/33 PP girls had a fibrinogen level above +2 SD from the control mean $(>3.75 \mathrm{~g} / \mathrm{L})$. This is noteworthy inasmuch as the longterm risk for a vascular disorder is known to be doubled or even tripled in individuals with circulating fibrinogen levels in the upper third of normal range compared with those with levels in the lower third $(17,41)$.

In conclusion, these data from young PP girls indicate that high plasma PAI-1-act levels may become an early marker for subsequent PCOS and its endocrine-metabolic correlates. It remains to be confirmed whether PAI-1-act has a similar predictive potential in non-PP girls. If so, then early PAI-1-act assessment may facilitate the design of early treatment studies aiming at prevention of PCOS in both PP and non-PP girls at high risk.

Acknowledgments. The authors thank Dr. Lluis Masana from The University Rovira i Virgili, Reus, Spain, for his methodological advice, Maria Jesús Gras for hormone measurements, and Inge Laleeuwe for editorial assistance.

\section{REFERENCES}

1. Ibáñez L, DiMartino-Nardi J, Potau N, Saenger P 2000 Premature adrenarchenormal variant or forerunner of adult disease? Endocr Rev 21:671-696

2. Ibáñez L, Potau N, Zampolli M, Riqué S, Saenger P, Carrascosa A 1997 Hyperinsulinemia and decreased insulin-like growth factor binding protein-1 are common features in prepubertal and pubertal girls with a history of premature pubarche. J Clin Endocrinol Metab 82:2283-2288

3. Ibáñez L, Potau N, Chacón P, Pascual C, Carrascosa A 1998 Hyperinsulinemia, dyslipidaemia and cardiovascular risk in girls with a history of premature pubarche. Diabetologia 41:1057-1063

4. Ibáñez L, de Zegher F, Potau N 1999 Anovulation after precocious pubarche: early markers and time course in adolescence. J Clin Endocrinol Metab 84:2691-2695

5. Ibáñez L, Potau N, Virdis R, Zampolli M, Terzi C, Gussinyé M, Carrascosa A, Vicens-Calvet E 1993 Postpubertal outcome in girls diagnosed of premature pubarche during childhood: increased incidence of functional ovarian hyperandrogenism. J Clin Endocrinol Metab 76:1599-1603

6. Dunaif A, Finegood DT $1996 \beta$-Cell dysfunction independent of obesity and glucose intolerance in the polycystic ovary syndrome. J Clin Endocrinol Metab 81:942-947

7. Legro RS, Kunselman AR, Dodson WC, Dunaif A 1999 Prevalence and predictors of risk for type 2 diabetes mellitus and impaired glucose tolerance in polycystic ovary syndrome: a prospective, controlled study in 254 affected women. J Clin Endocrinol Metab 84:165-169

8. Ehrmann DA, Barnes RB, Rosenfield RL, Cavaghan MK, Imperial J 1999 Prevalence of impaired glucose tolerance and diabetes in women with polycystic ovary syndrome. Diabetes Care 22:141-146

9. Mather KJ, Kwan F, Corenblum B 2000 Hyperinsulinemia in polycystic ovary syndrome correlates with increased cardiovascular risk independent of obesity. Fertil Steril 73:150-156

10. Wild S, Pierpoint T, McKelgue P, Jacobs H 2000 Cardiovascular disease in women with polycystic ovary syndrome at long-term follow-up: a retrospective cohort study. Clin Endocrinol 52:595-600

11. Ibáñez L, Potau N, Francois I, de Zegher F 1998 Precocious pubarche, hyperinsulinism and ovarian hyperandrogenism in girls: relation to reduced fetal growth. J Clin Endocrinol Metab 83:3558-3662

12. Ibáñez L, Potau N, de Zegher F 1999 Precocious pubarche, dyslipidemia, and low IGF binding protein-1 in girls: relation to reduced prenatal growth. Pediatr Res 46:320 322

13. Ibáñez L, Valls C, Potau N, Marcos MV, de Zegher F 2000 Sensitization to insulin in adolescent girls to normalize hirsutism, hyperandrogenism, oligomenorrhea, dyslipidemia, and hyperinsulinism after precocious pubarche. J Clin Endocrinol Metab $85: 3526-3530$

14. Ibáñez L, Valls C, Potau N, Marcos MV, de Zegher F 2001 Polycystic ovary syndrome after precocious pubarche: ontogeny of the low-birthweight effect. Clin Endocrinol 55:667-672

15. Sprengers DE, Kluft C 1987 Plasminogen activators and inhibitors. Blood 69:381387

16. Hamsten A, Wiman B, de Faire U, Blombäck M 1985 Increased plasma levels of a rapid inhibitor of tissue plasminogen activator in young survivors of myocardial infarction. N Engl J Med 313:1557-1563

17. Meade TW, Brozovic M, Chakrabarti RR, Haines AP, Imeson JD, Mellows S, Miller GJ, North WRS, Stirling Y, Thompson SG 1986 Haemostatic function and ischemic heart disease: principal results of the Northwick Park Heart Study. Lancet 2:533-537

18. Ernst E 1991 Fibrinogen. An independent risk factor for cardiovascular disease. BMJ 303:596-597

19. Kohler HP, Grant PJ 2000 Plasminogen-activator inhibitor type 1 and coronary artery disease. N Engl J Med 342:1792-1801

20. Byberg L, Keighe PM, Zethelius B, Lithell HO 2000 Birthweight and the insulin resistance syndrome: association of low birthweight with truncal obesity and raised plasminogen activator inhibitor-1 but not with abdominal obesity or plasma lipid disturbances. Diabetologia 43:54-60

21. Sampson M, Kong C, Patel A, Unwin R, Jacobs HS 1996 Ambulatory blood pressure profiles and plasminogen activator inhibitor (PAI-1) activity in lean women with and without the polycystic ovary syndrome. Clin Endocrinol 45:623-629

22. Atiomo WU, Bates SA, Condon JE, Shaw S, West JH, Prentice AG 1998 The plasminogen activator system in women with polycystic ovary syndrome. Fertil Steril 69:236-241

23. Juhan-Vague I, Alessi MC, Vague P 1991 Increased plasma plasminogen activator inhibitor I levels: a possible link between insulin resistance and atherothrombosis. Diabetologia 34:457-462

24. Juhan-Vague I, Alessi MC 1997 PAI-1, obesity, insulin resistance and risk of cardiovascular events. Thromb Haemost 78:656-660 
25. Potter van Loon BJ, Kluft C, Radder JK, Blankenstein MA, Meinders AE 1993 The cardiovascular risk factor plasminogen activator inhibitor type 1 is related to insulin resistance. Metabolism 42:945-949

26. Mansfield MW, Heywood DM, Grant PJ 1996 Circulating levels of factor VII, fibrinogen, and von Willebrand factor and features of insulin resistance in first-degree relatives of patients with NIDDM. Circulation 94:2171-2176

27. Juhan-Vague I, Roul C, Alessi MC, Ardissone JP, Heim M, Vague P 1989 Increased plasminogen activator inhibitor activity in non-insulin-dependent diabetic patientsrelationship with plasma insulin. Thromb Haemost 61:370-373

28. Barazzoni R, Zanetti M, Davanzo G, Kiwanuka E, Carraro P, Tiengo A, Tessari P 2000 Increased fibrinogen production in type 2 diabetic patients without detectable vascular complications: correlation with plasma glucagon concentrations. J Clin Endocrinol Metab 85:3121-3125

29. Marshall WA, Tanner JM 1969 Variations in the pattern of pubertal changes in girls. Arch Dis Child 44:291-303

30. Hammer LD, Kraemer HC, Wilson DM, Ritter PL, Dornbusch SM 1991 Standardized percentile curves of body-mass index for children and adolescents. Arch Pediatr Adolesc Med 145:259-263

31. Rosenfield RL 1994 Normal and almost normal precocious variations in pubertal development. Premature pubarche and premature thelarche revisited. Horm Res 41(suppl 2):7-13

32. New MI, Lorenzen F, Lerner AJ, Kohn B, Oberfield SE, Pollack MS, Dupont B, Stoner E, Levy DJ, Pang S, Levine LS 1983 Genotyping steroid 21-hydroxylase deficiency: hormonal reference data. J Clin Endocrinol Metab 56:320-325

33. Sakkal-Alkaddour H, Zhang L, Yang X, Chang YT, Kappy M, Slover RS 1996 Studies of $3 \beta$-hydroxysteroid dehydrogenase genes in infants and children manifesting premature pubarche and increased adrenocorticotropin-stimulated $\Delta^{5}$-steroid levels. J Clin Endocrinol Metab 81:3961-3965

34. The Expert Committee on the Diagnosis and Classification of Diabetes Mellitus 1997 Report of the Expert Committee on the Diagnosis and Classification of Diabetes Mellitus. Diabetes Care 20:1183-1197

35. Kluft C, Jie AFH, Rijken DC, Verheijen JH 1988 Daytime fluctuations in blood of tissue-type plasminogen activator (t-PA) and its fast-acting inhibitor (PAI-1). Thromb Haemost 59:329-332

36. Chmielewska J, Wiman B 1986 Determination of plasminogen activator and its "fast" inhibitor in plasma. Clin Chem 32:482-485

37. Dunaif A 1997 Insulin resistance and the polycystic ovary syndrome: mechanism and implications for pathogenesis. Endocr Rev 18:774-800

38. Velázquez EM, Mendoza SG, Wanf P, Glueck CJ 1997 Metformin therapy is associated with a decrease in plasma plasminogen activator inhibitor-1, lipoprotein (a), and immunoreactive insulin levels in patients with the polycystic ovary syndrome. Metabolism 46:454-457

39. Ehrmann DA, Schneider DJ, Sobel BE, Cavaghan MK, Imperial J, Rosenfield RL, Polonsky KS 1997 Troglitazone improves defects in insulin action, insulin secretion, ovarian steroidogenesis, and fibrinolysis in women with polycystic ovary syndrome. J Clin Endocrinol Metab 82:2108-2116
40. Glueck CJ, Wag P, Fontaine R, Tracy T, Sieve-Smith L 1999 Metformin-induced resumption of normal menses in 39 of $43(91 \%)$ previously amenorrheic women with the polycystic ovary syndrome. Metabolism 48:511-519

41. Juhan-Vague I 1996 Haemostatic parameters and vascular risk. Atherosclerosis 124(suppl):S49-S55

42. Wiman B 1996 Plasminogen activator inhibitor 1 in thrombotic disease. Curr Opin Hematol 3:372-378

43. Balasa VV, Gruppo RA, Glueck CJ, Stroop D, Becker A, Pillow A, Wang P 1999 The relationships of mutations in the MTHFR, prothrombin, and PAI-1 genes to plasma levels of homocysteine, prothrombin, and PAI-1 in children and adults. Thromb Haemost 81:739-744

44. Dawson S, Hamsten A, Wiman B, Henry A, Humphries S 1991 Genetic variation at the plasminogen activator inhibitor-1 locus is associated with altered levels of plasminogen activator inhibitor-1 activity. Arterioscler Thromb Vasc Biol 11:183190

45. Glueck CJ, Phillips H, Cameron D, Wang P, Fontaine RN, Moore SK, Sieve-Smith L, Tracy T 2000 The 4G/4G polymorphism of the hypofibrinolytic plasminogen activator inhibitor type 1 gene: an independent risk factor for serious pregnancy complications. Metabolism 49:845-852

46. Glueck CJ, Wang P, Fontaine RN, Sieve-Smith L, Tracy T, Moore SK 1999 Plasminogen activator inhibitor activity: an independent risk factor for the high miscarriage rate during pregnancy in women with polycystic ovary syndrome. Metabolism 48:1589-1595

47. Iacoviello L, Burzotta F. di Castelnuovo A, Zito F, Marchioli R, Donati MB 1998 The $\mathrm{G} / 5 \mathrm{G}$ polymorphism of PAI-1 promoter gene and the risk of myocardial infarction: a meta-analysis. Thromb Haemost 80:1029-1030

48. Alessi MC, Juhan-Vague I, Kooistra T, Declerck PJ, Collen D 1988 Insulin stimulates the synthesis of plasminogen activator inhibitor 1 by the human hepatocellular cell line Hep G2. Thromb Haemost 60:491-494

49. Schneider DJ, Sobel BE 1996 Synergistic augmentation of expression of plasminogen activator inhibitor type-1 induced by insulin, very-low-density lipoproteins, and fatty acids. Coronary Artery Dis 7:813-817

50. Nordt TK, Sawa H, Fujii S, Sobel BE 1995 Induction of plasminogen activator inhibitor type-1 (PAI-1) by proinsulin and insulin in vivo. Circulation 91:764-770

51. Folsom AR, Qamhieh HT, Wing RR, Jeffery RW, Stinson VL, Kuller LH, Wu KK 1993 Impact of weight loss on plasminogen activator inhibitor (PAI-1), factor VII, and other hemostatic factors in moderately overweight adults. Arterioscler Thromb 13:162-169

52. Sironi L, Mussoni L, Prati L, Baldassarre D, Camera M, Banfi C, Tremoli E 1996 Plasminogen activator inhibitor-1 (PAI-1) synthesis and mRNA expression in HepG2 cells are regulated by VLDL. Arterioscler Thromb Vasc Biol 16:89-96

53. Folsom AR, Wu KK, Davis CE, Conlan MG, Sorlie PD, Szklo M 1991 Population correlates of plasma fibrinogen and factor VII, putative cardiovascular risk factors. Atherosclerosis 91:191-205 